\title{
Modeling and Simulation of Power MOSFET Using Orcad-Pspice
}

\author{
Messaadi Lotfi and Dibi Zohir \\ Advanced Electronic Laboratory (LEA), Faculty of Technology, Department of \\ Electronic, University of Batna, Algeria \\ lotfi.messaadi@gmail.com,zohirdibi@yahoo.fr
}

\begin{abstract}
This paper provides a macromodel in Pspice (Personal Simulation Program with Integrated Circuit Emphasis) for a trench power MOSFET rated at $70 \mathrm{~V}$ over a temperature range of $-55^{\circ} \mathrm{C}$ to $175^{\circ} \mathrm{C}$. The Pspice macromodel was built using device parameters extracted through experiment. The static behavior of the trench power MOSFET is simulated and compared to the measured data to show the accuracy of the Pspice model. The temperature dependent behavior was simulated and analyzed.
\end{abstract}

Keywords: Power trench MOSFET, Modeling, DC characteristic, Spice macromodeling, Simulation, Power Devices, Temperature variation effect, PSpice

\section{Introduction}

Power MOSFETs are an important class oF discrete devices used in a variety of power conversion applications for a voltage range of below $200 \mathrm{~V}$, because they have low conduction power loss, high input impedance, and high switching speed [1-4]. The increasing popularity of power MOSFETs has led to greater efforts to try to reduce their specific on-resistance, to minimize die sizes, and to reduce cost, especially for low voltages of less than $50 \mathrm{~V}$. This has been largely driven by the increasing demand for portable electronics, such as personal computers and cellular telephones, with high performance, small size, and extended battery life.

A trench gate MOSFET is the most preferred power device for medium to low voltage power applications [2]. These are used extensively in control switching, DCDC converters, automotive electronics, microprocessor power supplies etc., In all these applications, low on-state resistance is the prime requirement to reduce the conduction power loss and forward voltage drop. Higher drive current, low gate-todrain capacitance, high transconductance, high breakdown voltage and inductive switching capability are the other requirements in various applications of power MOSFETs [3]. Different techniques have been proposed for reducing the on-state resistance and improving other performance parameters [4].

In this paper, we present the structure of the proposed device with its simulations. Using DC analysis simulations performed with Spice simulator, we present an extensive analysis of the proposed device in contrast with the conventional device, showing that the proposed device exhibits improved drive current and transconductance and reduced on state resistance as compared to the conventional device.

\section{Modeling Of Basic Trench Power MOSFET} 1.

A basic trench MOSFET structure with a cell pitch of $2.5 \mu \mathrm{m}$ is shown in Figure 


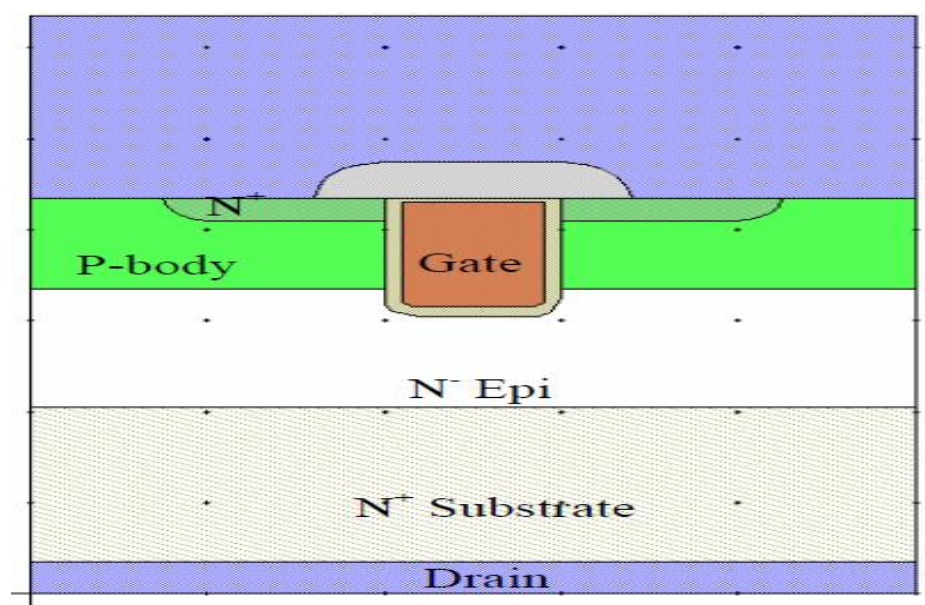

Figure 1. Trench MOSFET Structure

To accurately reproduce the behavior of the trench MOSFETs in real circuit operation, we have carefully chosen the physical models and model parameters used in Spice simulation, such as carrier mobility and lifetime. The trench MOSFET model was validated by comparing to measurement data of real devices [5].

\section{Output Characteristics}

The device operates in the first quadrant when a positive voltage is applied to the drain. As the gate voltage $\left(\mathrm{V}_{\mathrm{G}}\right)$ increases above the threshold voltage $\left(\mathrm{V}_{\mathrm{TH}}\right)$, the MOSFET channel begins to conduct current. The amount of current it conducts depends on the on-resistance of the MOSFET, as defined by:

$$
R_{D S(O n)}=V_{D} / I_{D}
$$

For sufficiently large gate overdrive $\left(V_{G} \gg V_{T H}\right)$, the $I_{D}-V_{D}$ curve appears linear because the MOSFET channel is fully turned on. Under low gate overdrive, the drain current reaches a saturation point when $\mathrm{V}_{\mathrm{D}}>\left(\mathrm{V}_{\mathrm{G}}-\mathrm{V}_{\mathrm{TH}}\right)$ due to a pinch-off effect of the channel.

\section{On-Resistance}

The on-state resistance of a power trench MOSFET is made up of several components as shown in Figure 2:

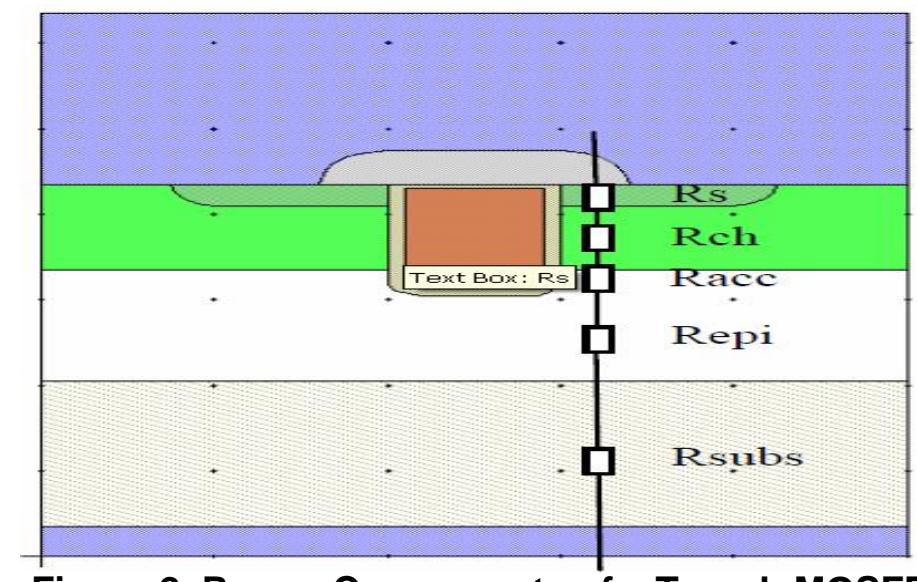

Figure 2. $\mathbf{R}_{\mathrm{DS}(\mathrm{ON})}$ Components of a Trench MOSFET 


$$
R_{D S}(\text { on })=R_{S}+R_{C H}+R_{A C C}+R_{E p i}+R_{\text {Subs }}
$$

$\mathrm{R}_{\mathrm{S}}$ : source resistance

$\mathrm{R}_{\mathrm{CH}}$ : channel resistance

$\mathrm{R}_{\mathrm{ACC}}$ : resistance from the accumulation region

$R_{\text {Epi: }}$ resistance from the top layer of silicon (epitaxial silicon, also known as epi); epi controls the amount of blocking voltage the MOSFET can sustain.

$\mathrm{R}_{\text {Subs: }}$ : resistance from the silicon substrate on which the epi is grown.

The equation that represents $\mathrm{R}_{\mathrm{DS}(\mathrm{ON})}$ vs. temperature

$$
R_{D s(o n)}(T)=R_{D s(o n)}\left(25^{\circ} \mathrm{C}\right)\left[1+\frac{\alpha}{100}\right]^{(T-25)}
$$

With $\alpha$ calculated via a curve fitting routine. This expression gets implemented in the Spice model.

\section{Threshold Voltage}

Threshold voltage, $\mathrm{V}_{\mathrm{GS}}(\mathrm{TH})$ is defined as the minimum gate bias which can form a conducting channel between the source and drain. For power trench MOSFETs, it is usually measured at the drain-source current of $250 \mu \mathrm{A}$. Gate oxide thickness and doping concentration of the channel can be used to control the V. Typically, 2 4V is designed for gate drive of $10-15 \mathrm{~V}$. With the scaling down of the CMOS technology [9-11], the gate drive of the power trench MOSFET drops to 2.5-4.5V. Therefore, lower threshold voltages of $2-5 \mathrm{~V}$ are needed for these applications.

The voltage source that represents the temperature dependence of Vth (threshold voltage)

$$
V_{t h}(T)=V_{t h}\left(25^{\circ} \mathrm{C}\right)+\xi\left(T-25^{\circ} \mathrm{C}\right)
$$

With $\xi=-8.5 \mathrm{mV} /{ }^{\circ} \mathrm{C}$

Expression used in model

Table 1, shows the electrical parameter comparison between the "virtual" trench power MOSFET and its real world counterpart; reasonable agreement is observed.

\begin{tabular}{|c|c|c|}
\hline \multirow[t]{2}{*}{ Device parameters } & \multicolumn{2}{|c|}{ Basic Trench MOSFET } \\
\hline & Modeled & Measured \\
\hline$B V_{D S S}(V) @ I_{D}=250 u A(V)$ & 70.35 & 70 \\
\hline $\mathbf{V}_{\mathrm{TH}} @ \mathbf{I}_{\mathrm{D}}=\mathbf{2 5 0 u A}(\mathbf{V})$ & 3.18 & 3 \\
\hline $\operatorname{RDS}(\mathrm{ON})_{0} \mathrm{~V}_{\mathrm{GS}}=10 \mathrm{~V}(\mathrm{~m} \Omega)$ & 9.10 & 9.50 \\
\hline
\end{tabular}

\section{Table 1. Comparison of Simulated and Measured Electrical Parameters of the Basic Trench Power MOSFET}

With a few minor exceptions, remarkable agreement has been demonstrated when product characterization and simulated MOSFET behavior is compared [6].

\section{Proposed Model Trench Power MOSFET}

The proposed model shows in Figure 3, was initially developed for the design of very low-power analog ICs. With the objective of having a simple analytical model valid in all modes of inversion. It was important to correctly handle the weak inversion part since many micro power circuits were designed based on the MOS transistor operating in this region. 


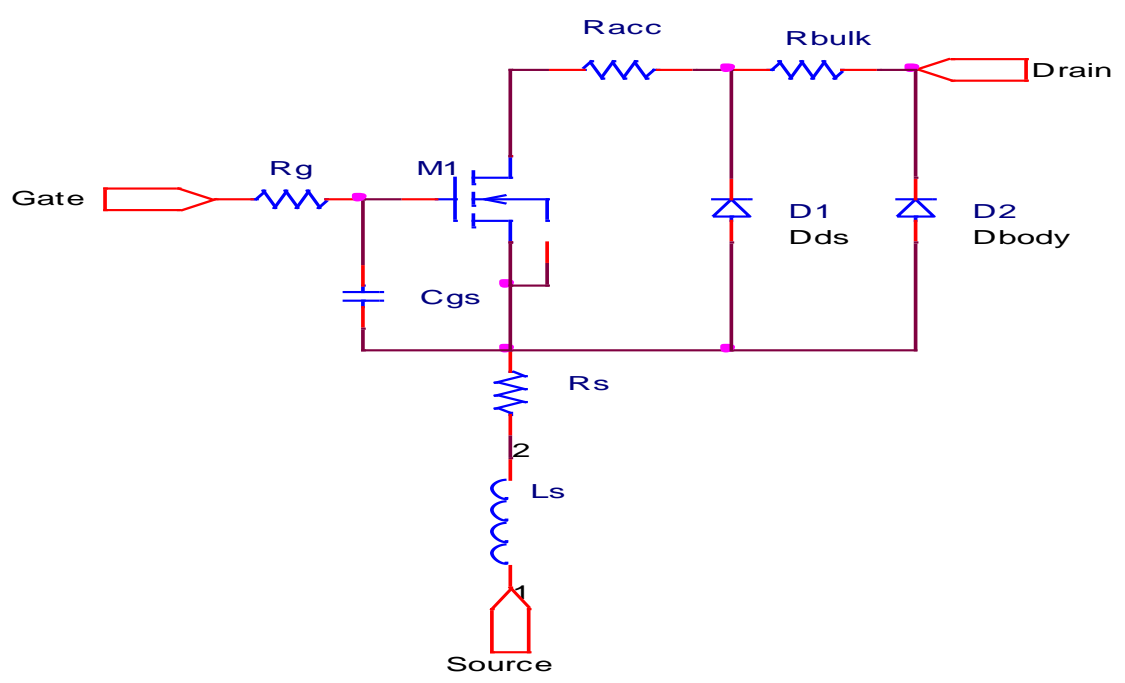

Figure 3. New SPICE ABM Trench Power MOSFET Model

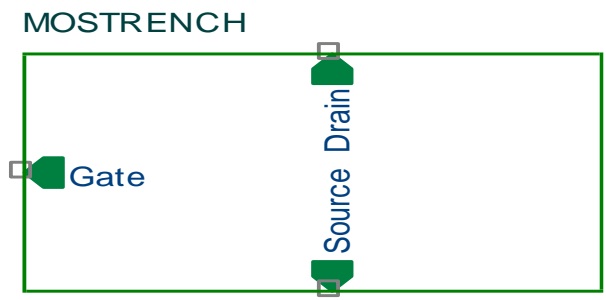

Figure 4. MOSFET Model Created in PSPICE Library

\section{Simulations Results}

The results of two-dimensional numerical simulations on the $70 \mathrm{~V} / 70 \mathrm{~A}$ trench power MOSFET structure are described here to provide a more detailed understanding of the underlying device physics and operation.

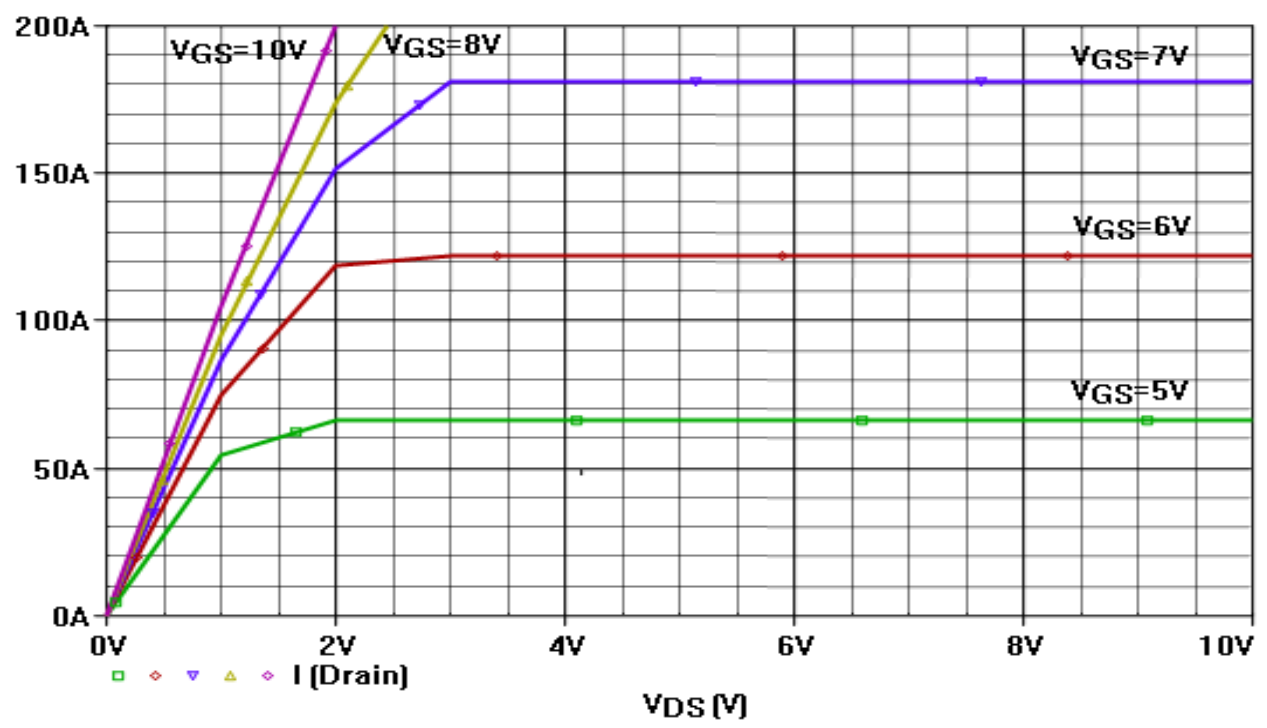

Figure 5. Forward Characteristic Simulation and of 70 V / 70 A Trench Power MOSFET at $27^{\circ} \mathrm{C}$ 


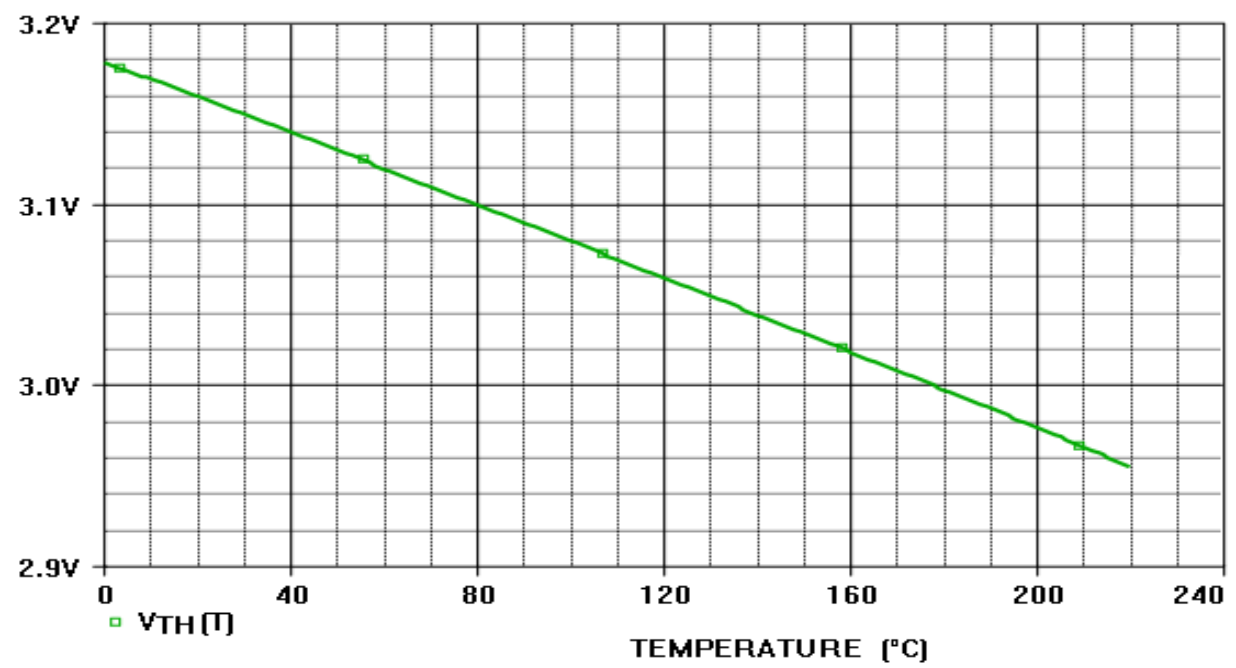

Figure 6. Threshold Voltage Simulation of 70 V / 70 A Trench Power MOSFET

The value of threshold voltage $\left(\mathrm{V}_{\mathrm{TH}}\right)$ show in Figure 6, were directly obtained from simulation curve transfer, threshold voltage decreases with increasing temperature.

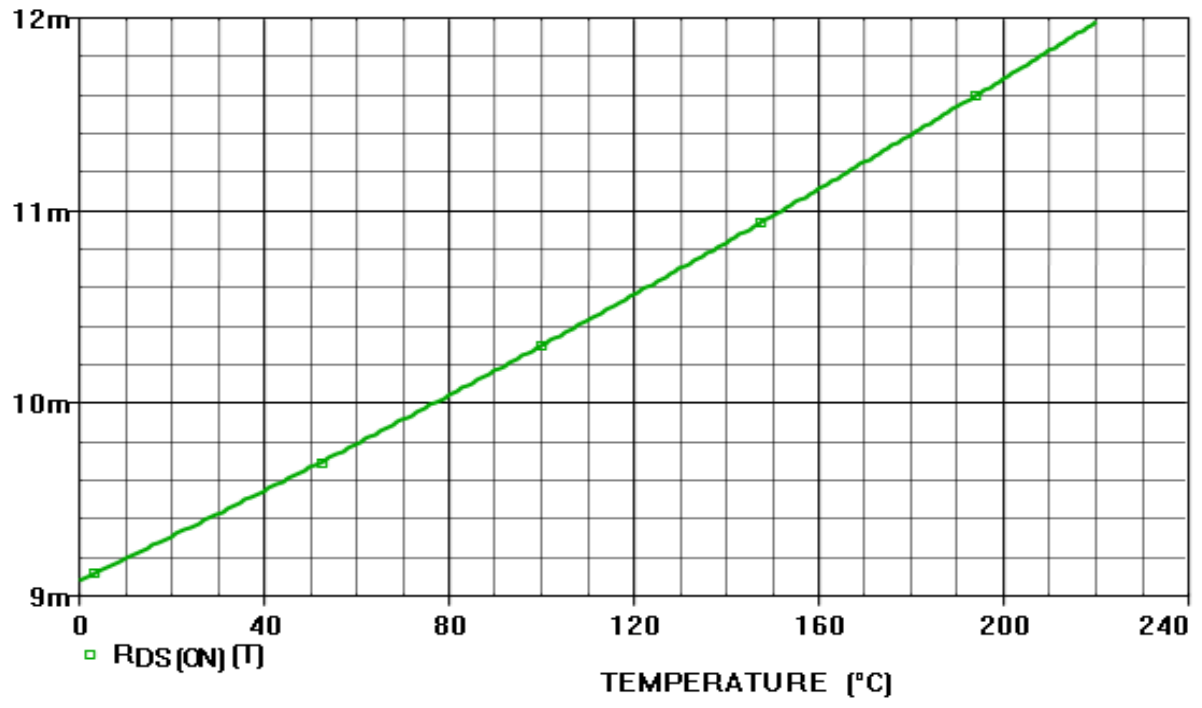

Figure 7. On-State Resistance Simulation of 70 V / 70 A Trench Power MOSFET

The On-state resistance can be calculated from the forward curves. As shown in Figure 7, around $0{ }^{\circ} \mathrm{C}$, the on-state resistance from the curve is $9.1 \mathrm{~m} \Omega / \mathrm{cm}^{2}$ and at $\mathrm{T}=220^{\circ} \mathrm{C}$ the $R_{\mathrm{DS}(\mathrm{ON})}=12 \mathrm{~m} \Omega / \mathrm{cm}^{2}$, as expected, the model device shows lower on resistance as compared to the conventional device. 


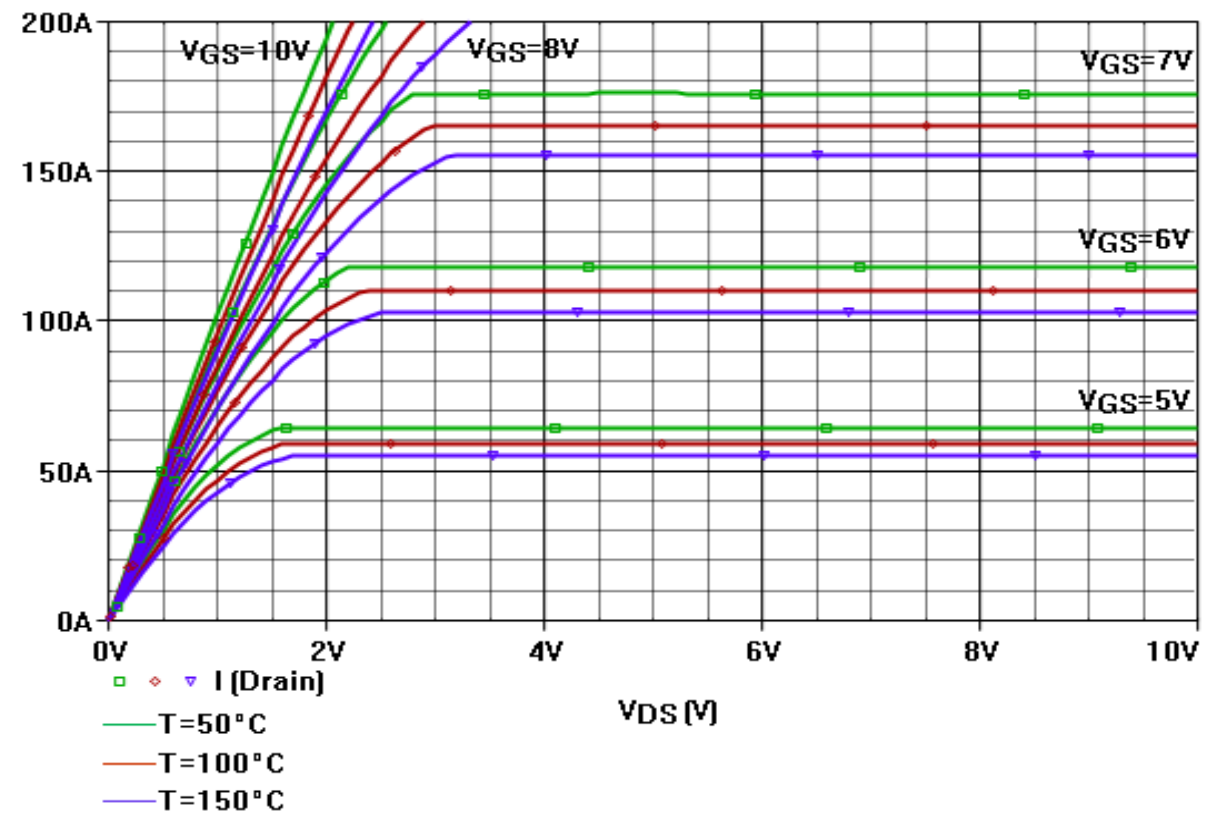

Figure 8. The $I_{D S}-V_{D S}$ characteristics of trench power MOSFET at the $T=50^{\circ} \mathrm{C}$, $100^{\circ} \mathrm{C}$ and $150^{\circ} \mathrm{C}$ respectively

Figure 8 , show the output characteristics for model simulated at $50^{\circ} \mathrm{C}, 100^{\circ} \mathrm{C}$ and $150^{\circ} \mathrm{C}$, respectively.

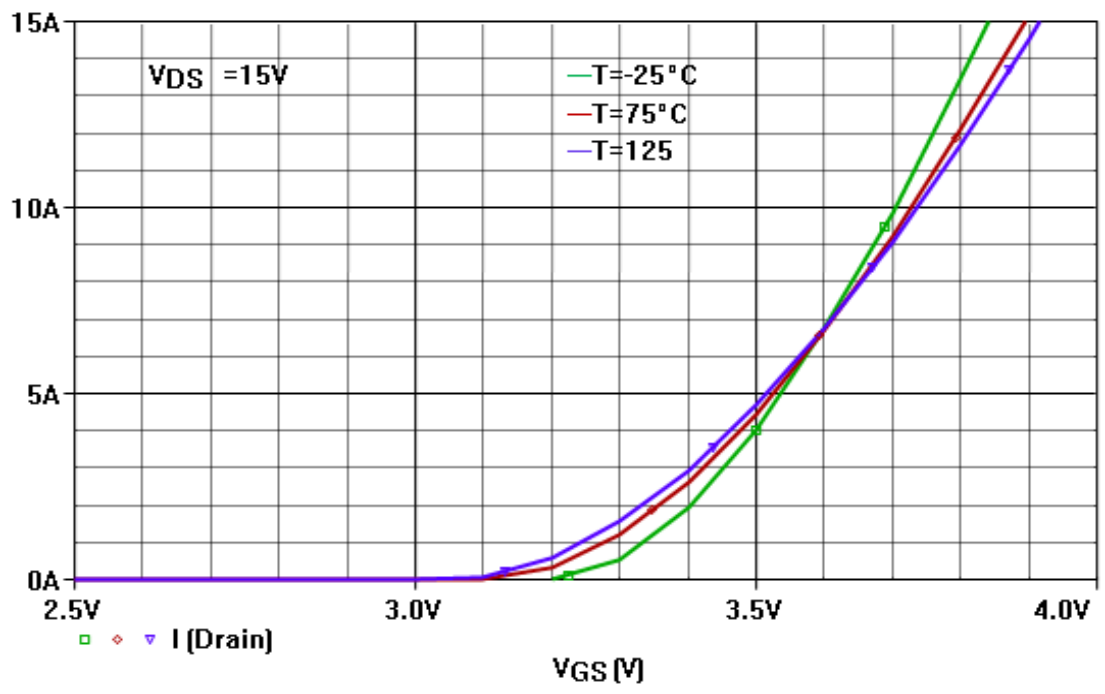

Figure 9. Transfer Characteristic Simulation with Model

Simulated transfer curves have also been simulated at different temperatures in Figure 9. Clearly, this model gives more satisfactory results compared to the model built shown in Figure 3. The transcondunctance can be calculated from the transfer curve, which increases with temperature, 


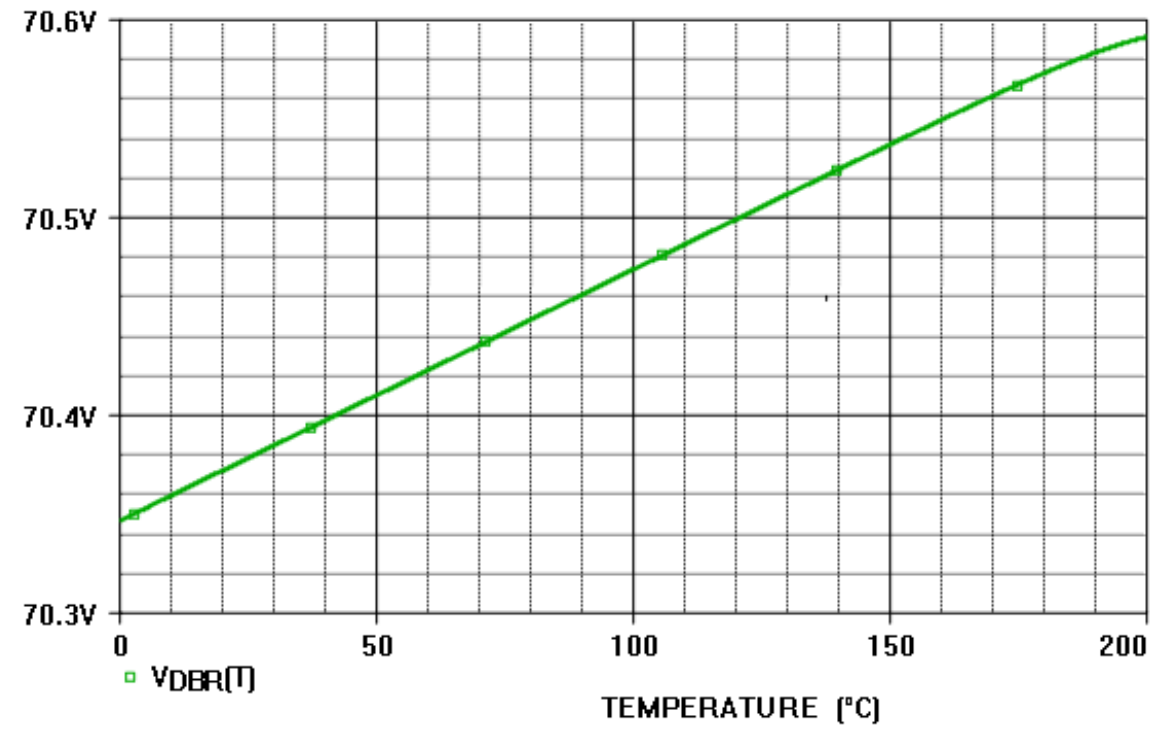

\section{Figure 10. Simulation Drain to Source Breakdown Voltage vs. Junction Temperature}

Temperature-voltage characteristics of a power MOSFET are shown in Figure. $10 . \mathrm{V}_{\mathrm{DBR}}$ is measured at $250 \mu \mathrm{A}$ drain current.

\section{Conclusion}

A model has been developed to explain the behavior of the trench power MOSFET output characteristics at different temperatures. It includes the change in the threshold voltages, carrier mobility, the body leakage current, and the drain and source contact resistances. The MOSFET output characteristics and parameter values are compared with previously measured experimental data. There is a good agreement between the model outputs and the experimental data. The model can be used to predict the MOSFET characteristics with change of temperature.

\section{References}

[1] R. P. Zingg, "On the Specific On-Resistance of High-Voltage and Power Devices", IEEE Trans. Electron Devices, vol. 51, no. 3, (2004) Mar., pp. 492-499.

[2] X. Luo, T. F. Lei, Y. G. Wang, G. L. Yao, Y. H. Jiang, K. Zhou, P. Wang, Z. Y. Zhang, J. Fan, Q. Wang, B. Z. R. Ge, Z. Li and F. Udrea, "Low on-resistance SOI dual-trench-gate MOSFET", IEEE Trans. Electron Devices, vol. 59, (2012) Feb., pp. 504-509.

[3] Y. K. Cho, T. M. Roh and J. Kim, "A New Strained-Si Channel Power MOSFET for High Performance Applications”, ETRI Journal, vol. 28, no. 2, (2013) April, pp. 253-256.

[4] J. Kim, T. M. Roh, S. G. Kim, Y. Park, Y. S. Yang, D. W. Lee, J. G. Koo, K. I. Cho and Y. Kang, "A Novel Process for Fabricating High Density Trench MOSFETs for DC-DC Converters”, ETRI Journal, vol. 24, no. 5, (2002) Oct, pp. 333-340.

[5] M. H. Juang, W. C. Chueh and S. L. Jang, "The formation of trench-gate power MOSFETs with a SiGe channel region", Semicond. Sci. Technol., vol 21, no. 6, (2006) May, pp. 799-802.

[6] Y. Singh and M. Punetha, "A Lateral Trench Dual Gate Power MOSFET on Thin SOI for Improved Performance”, ECS J. of Solid State Sci. and Tech., vol. 2, no. 7, (2013) May, pp. Q113-Q117.

[7] D. Ueda, H. Takagi and G. Kano, "A New Vertical Power MOSFET Structure with Extremely Reduced On-Resistance", IEEE Trans. Electron Devices, vol. 32, no. 1, (1985) Jan, pp. 2-6.

[8] R. S. Saxena and M. J. Kumar, "A Novel Dual Gate Strained-Silicon Channel Trench Power MOSFET for Improved Performance", Accepted in 2008 NSTI Nanotechnology Conference and Trade Show, Boston, Massachusetts, U.S.A, (2008) June 1-5. 
[9] K. Varadarajan, A. Sinkar and T. Chow, "Novel Integrable 80V silicon lateral trench power MOSFETs for high frequency DC-DC converters", in Power Electronics Specialists Conference, (2007) Jun., pp. $1013-1017$.

[10] R. Kraus and H. J. Mattausch, "Status and trends of power semiconductor device models for circuit simulation”, IEEE Trans. PEL, vol. 13, no. 3, (1998) May, pp. 452-465.

[11] J. G. Kassakian, "Automotive electrical systems - the power electronics market of the future", IEEE APEC Rec., (2000) February, pp. 3-9.

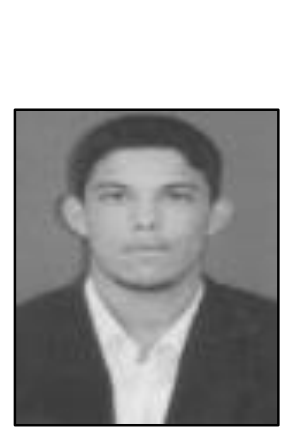

\section{Authors}

Messaadi Lotfi, was born in Batna, Algeria in 1985. He received his Engineering degree and magister in electronics from University of Batna, Algeria in 2007 and 2009 respectively. Currently, he is a PhD student. His interests include modeling and simulation of electronic and power electronic components using recent simulators.

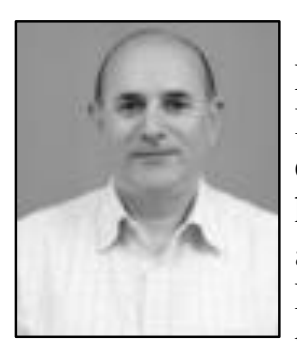

Dibi Zohir, Professor in the department of electrical and Electronic Engineering and vice-rector for pedagogical activities of Batna university. He received his B.S. degree in Electronics engineering from the university of Setif, Algeria in 1994, he received his MEng and $\mathrm{PhD}$ degrees from the Constantine university in 1998 and 2002, respectively. In 2009 he received his professor degree. From 2003 to 2009 he was Head of Electronics department, His research interests include neuronal networks, sensors, and smart sensors, modeling of electronic devices. 